\title{
A FESTA COMO POSSIBILIDADE DE DISPUTA DE TERRITÓRIO
}

\section{THE PARTY AS A POSSIBILITY OF TERRITORY DISPUTE}

\author{
SANFILIPPO, Lucio Bernard ${ }^{1}$
}

\begin{abstract}
RESUMO
O presente artigo pretende apontar caminhos para a discussão da festa e suas potências. Percorre os caminhos de transbordamento das ideias da pesquisa de mestrado para o doutorado (em andamento) do autor, discutindo as possibilidades das festas, não só como espaços e tempos de confraternização e celebração, mas de disputa da cidade. Aponta também as tessituras de redes educativas e processos culturais envolvidas na produção das festas, bem como assume o corpo como território de produção de conhecimentos, força e liberdade. Na transição entre as pesquisas de mestrado e doutorado em Educação na linha de Cotidianos, Redes Educativas e Processos Culturais, ressalta a importância de uma metodologia em movimento, sensível a cada encontro com os sujeitos, em observação participante e conversas interativas.
\end{abstract}

PalaVRas-Chave: Festa; Corpo; Terreiro; Religiosidade; Redes educativas.

\section{ABSTRACT}

The present article intends to point out ways for the discussion of the party and its powers. Based on the ideas presented in the author's ideas and his doctorate in progress, this text discusses the possibilities of parties being understood as spaces and times of confraternization and celebration and also of dispute of the city. It also indicates the tessitures of educational networks and cultural processes involved in the production of parties, as well as the body as a territory for the production of knowledge, strength and freedom. In the transition between master's and doctoral research in Education, in the Line of Daily Life, Educational Networks and Cultural Processes, the research emphasizes the importance of a methodology in movement, sensitive to each encounter with the subjects, in participant observation and interactive conversations.

KeYwORDS: Party; Body; Terreiro; Religiosity; Educational networks.

\section{FESTA TRANSBORDADA}

Os momentos passados no interior da igreja do Rosário dos Pretos no Pelourinho em maio de 2016 ainda estão muito vivos na memória. Ainda vejo o padre anunciando que aquela missa, a de São Jorge, a de Oxóssi ${ }^{2}$, tinha sido encomendada "pelos irmãos da Casa Branca". Ainda ouço Mãe Sinha, a ekede de

\footnotetext{
${ }^{1}$ Doutorando em Educação Kekére / Proped / UERJ; Cantor; Professor de Educação Física.

${ }^{2}$ Oxóssi, o Orixá - deus Iorubá - mítico Rei de Ketu e Caçador de uma flecha só.
} 
e-Mosaicos - Revista Multidisciplinar de Ensino, Pesquisa, Extensão e Cultura do Instituto de Aplicação Fernando Rodrigues da Silveira (CAp-UERJ)

V. 7 - N. 14 - ABRIL 2018 - ISSN: 2316-9303

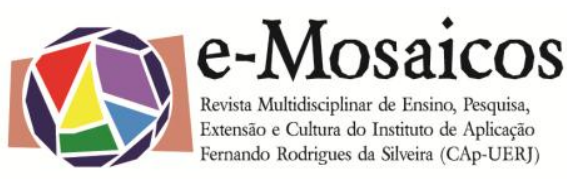

DOI: $10.12957 /$ e-mosaicos.2018.33325

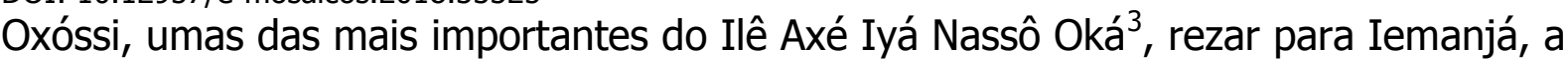
mãe do dono do dia.

Figura 1: Ekede Sinha, da Casa Branca, acompanha a entrada de Oxóssi nas mãos e uma ekede na Igreja de Nossa Senhora do Rosário dos Homens Pretos, no Pelourinho, Salvador-BA

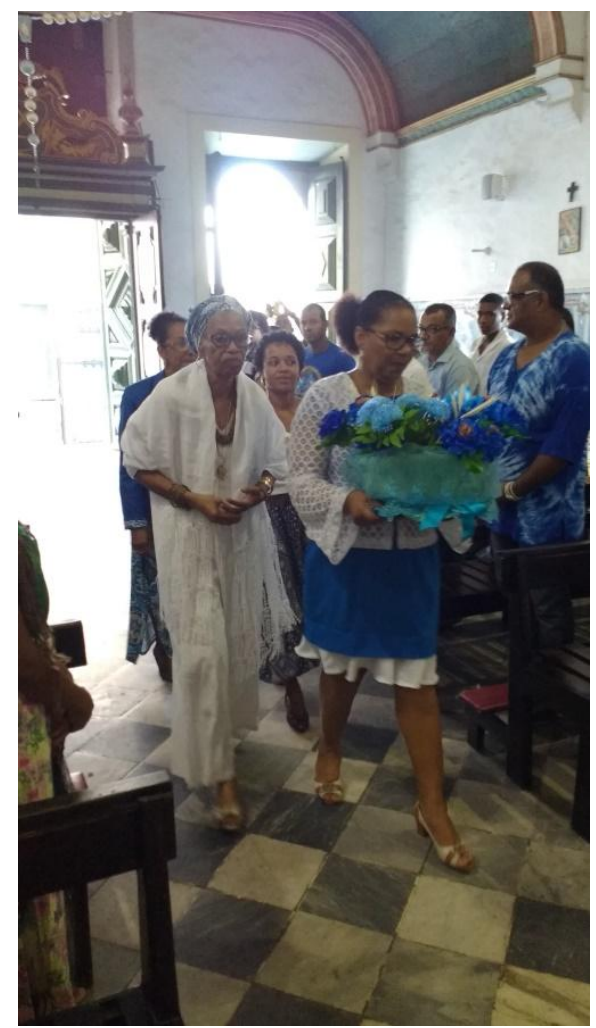

Fonte: Acervo do Autor.

Os atabaques tocavam durante a missa na igreja - uma das tantas que negras e negros, sequestradas e sequestrados de suas terras de lá e escravizadas e escravizados nessas de cá - construíram e nas quais não podiam entrar. Eu pensava em como Oxóssi, naquele dia, ocupava aquele lugar, em como seus filhos faziam sua festa onde, antes, não era bem vindo. E esperava ansioso pela saída da igreja para a roça ${ }^{4}$, pois já havia ouvido falar de como era encantada a subida da escadaria ao som do Agueré5. Chegando lá, ainda do meio da rua, ouviam-se os clarins que

\footnotetext{
${ }^{3}$ Também conhecido como Casa Branca do Engenho Velho, tido como a primeira casa de candomblé de que se tem registro no Brasil.

${ }^{4}$ Como são também chamados pelos fiéis os terreiros de candomblé;

${ }^{5}$ Sobre o complexo cultural Agueré, que é também ritmo, toque, canto, festa..., conferir AGUERÉ: caminhos de transbordamento na afro-diáspora, dissertação de mestrado que apresentei ao PROPEd/UERJ, sob orientação de Mailsa Passos e bolsa do $\mathrm{CNPq}$, disponível em
} 
e-Mosaicos - Revista Multidisciplinar de Ensino, Pesquisa, Extensão e Cultura do Instituto de Aplicação Fernando Rodrigues da Silveira (CAp-UERJ)

V. 7 - N. 14 - ABRIL 2018 - ISSN: 2316-9303

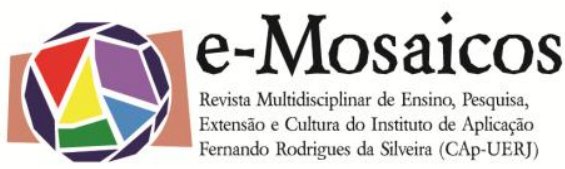

DOI: $10.12957 /$ e-mosaicos.2018.33325

acompanhavam os toques dos atabaques e anunciavam a chegada do Rei Caçador. O dono da festa e seus convidados iam "virando" nas cabeças e nos corpos de seus filhos ainda na escadaria.

Eu estava em Salvador, no último semestre do Mestrado do PropEd/UERJ, pesquisando os Caminhos do Agueré e seus transbordamentos na afro-diáspora. Entendi, na pesquisa, como transbordamento (SANFILIPPO, 2016), que o Agueré um complexo cultural do Orixá Oxóssi que chamo assim porque é toque, canto, dança, festa, entre outras potências - é tão rico e grandioso que não pôde ser contido dentro dos terreiros de candomblé, nem pelas proibições da polícia na época da criação da religião: ele transbordou!

Transbordando, irrigou por tempos e espaços da afro-diáspora, principalmente o caso brasileiro, outras tantas belas e ricas manifestações, como maracatus, blocos afro-baianos, levadas de violão de astros pop, baterias de escolas de samba, viradas de berimbaus... Terminei o Mestrado certo de que nessas manifestações, as memórias ancestrais transbordavam pelos corpos, por intermédio dos quais eu sentia as vibrações do Agueré. Foi essa uma das razões pelas quais eu quis conhecer um pouco de alguns desses caminhos de transbordamento. Acabei saindo da defesa com a ideia de continuar a pesquisa e transformar em livro e filme, projeto que tenho ainda comigo e que em poucos anos coloco em prática, pois logo emendei o doutorado e outras ideias de transbordamento me ganharam os pensamentos.

Durante todo o trabalho, eu refletia sobre como o candomblé me permitia o reencantamento do dia a dia: os cheiros, as cores, as texturas, os sons, os gestos, os cantos, as danças, as comidas, as roupas, os atabaques, os laços, os mitos, os ritos... (CAPUTO, 2012) as lembranças todas me possibilitavam encher de poesia o cotidiano da pesquisa e eu lamentava que isso fosse tão distante de tantas e tantas pessoas. Pensei em quanto a escola perdia por não conhecer mais a fundo essas realidades afro-brasileiras da diáspora, quanto estariam deixando de se orgulhar de fazer parte de um universo tão sofisticado e grandioso. Conhecer esse universo é começar a entender como, apesar de todas as mazelas, as pessoas têm recriado seus universos, redimensionado suas vidas, produzido um sem fim de conhecimentos em forma de belezas e riquezas, como têm cantado, tocado, dançado, costurado, cozinhado, contado e recontado suas histórias fazendo FESTA.

A ideia fixa da festa me fez pensar para o Doutorado, inicialmente, em fazer conversarem as festas do candomblé e da escola, pensar nas potências desses processos, levando sempre em consideração os sentidos de que falei anteriormente: cheiros, sabores, sons, olhares, texturas e as redes educativas que se estabeleciam... Queria entender onde mais o corpo poderia contribuir nos processos pedagógicos escolares e como o candomblé poderia se enxergar mais nos ambientes escolares.

http://www.academia.edu/28345528/Aguer\%C3\%A9 caminhos de transbordamento na afrodi\%C3\%A1spora

${ }^{6}$ Como é também chamada a incorporação no candomblé 
e-Mosaicos - Revista Multidisciplinar de Ensino, Pesquisa, Extensão e Cultura do Instituto de Aplicação Fernando Rodrigues da Silveira (CAp-UERJ)

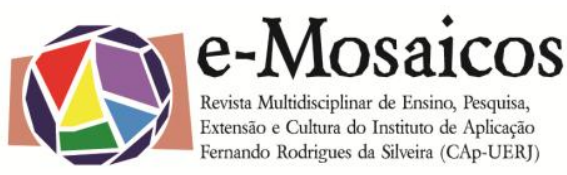

DOI: $10.12957 /$ e-mosaicos.2018.33325

Mas era pouco. A exemplo do Agueré, e de outros tantos complexos culturais infinitamente ricos e belos, a festa também transborda.

\section{A Defesa}

A vocação festiva de nosso povo, sentida de maneira incisiva nas manifestações afro-brasileiras, transborda com o corpo e suas memórias e se estabelece neste e com este corpo pelos espaços e tempos. Ser de candomblé me faz perceber isso, quase que naturalmente. Mais que isso, como disse Seu Tiãozinho da Mocidade (SANFILIPPO, 2016), o candomblé e as senhoras mães de santo, nos deram o "jeito alegre de ser" que me faz ainda mais um ser festivo. Ou festeiro, como me batizou a saudosa Zezé do Folclore, já em 1997, ao começar a licenciatura plena em Educação Física: "Lucio já chegou aqui festeiro."

Para a defesa da dissertação, criei um evento no Facebook. Muitas confirmações de presença e a preocupação com a lotação do lugar. Não podíamos dispor da UERJ por conta das Olimpíadas, prazo terminando, conseguimos um belo lugar com a querida amiga Doutora Camila do Valle. Sabia que muita gente aguardava ansiosa por assistir e ler o que a pesquisa dos caminhos de transbordamento do Agueré tinha me ajudado a produzir. Pareceu-me normal pensar nos ogãs da minha casa de santo tocando o Agueré nos atabaques devidamente enfeitados com laços azuis - enquanto eu cantava para Oxóssi os transbordamentos que sua realeza tem inspirado por terras e tempos brasileiros. Também pareceu-me natural que houvesse as comidas preferidas do Rei e de seus irmãos Orixás, e seus transbordamentos culinários: axoxô, omolocum, acarajé, caruru, cocada, quindim, pé-de-moleque, vatapá, bobó de camarão. O cheiro da comida tomava o lindo MAST - Museu de Astronomia que, como previsto, lotou. Quase 100 pessoas assinaram a lista de presença e muitas sentaram no chão para assistir - o que para quem é de candomblé nunca foi e nem será problema.

Figura 2: Ogãs Anderson, Marcello, Caio, Marcos e Bryan. Atabaques "vestidos" para Oxóssi na defesa de Mestrado, no MAST



Fonte: Foto Marisa Silva, cedida ao Autor. 


\section{Figura 3: Comidas na Defesa de Mestrado, no MAST}

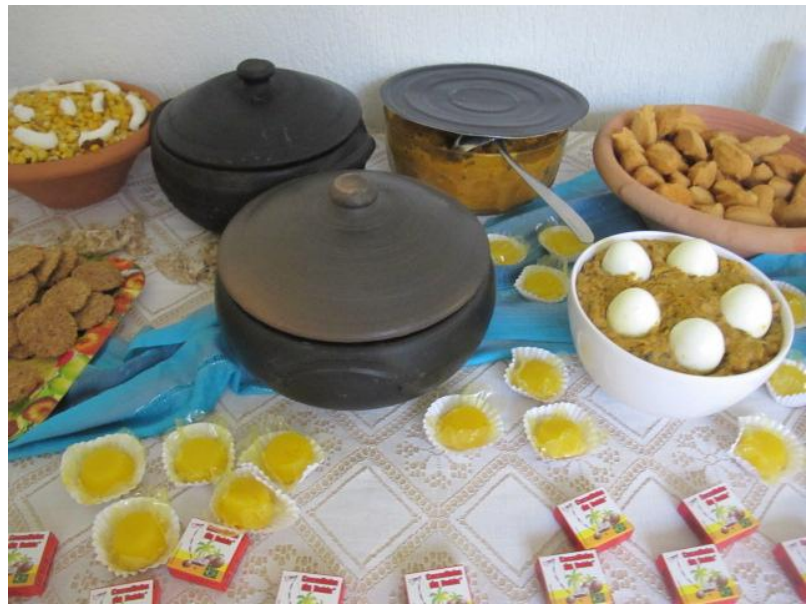

Fonte: Foto Marisa Silva, cedida ao Autor.

Dias antes da defesa, minha orientadora do Mestrado Mailsa Passos me telefonou: "Lucio, não gostaria que se fizesse festa antes da defesa, porque há um protocolo e festejar antes pode parecer que estamos atropelando o processo ainda não encerrado". Foi mais ou menos assim que ela mostrou sua preocupação. A resposta, automática, levou-me a perceber que eu já havia ido além dos transbordamentos do Agueré: "A Festa é a própria pesquisa, é a própria defesa. Não tem como ser diferente. Enquanto em outras defesas, há empadinhas no coquetel do final, na minha, tem que ter como ajeum ${ }^{7}$ o axoxô. Em uma das defesas, berimbau e ladainha de capoeira, na minha, atabaque e Agueré. Não se preocupe. A Festa é o próprio trabalho.". Senti seu alívio do outro lado da linha e pude imaginar seu sorriso.

A potência da festa se havia mostrado pra mim transbordada para além do Agueré, já tão complexo, rico e belo. Era ela a estrela desde sempre. O Agueré é a uma festa do povo de santo, a festa do Caçador, do Rei de Ketu, do povo nagô no Brasil. É o canto, a dança, o café da manhã do dia de Corpus Christi. É a missa na Igreja do Rosário dos Pretos, é a subida da escadaria da Casa Branca no Engenho Velho da Federação. É a cozinha, o sabor e o cheiro do milho e do coco, os panos azuis, o som dos oguês ${ }^{8}$ acordando o dono da festa. É o Leão Coroado de Pernambuco, o Ilê Ayê e o Olodum da Bahia, a Portela e a Mocidade do Rio de Janeiro. É a defesa da dissertação, o filme e o livro que ainda estão por vir.

\footnotetext{
${ }^{7}$ Ajeum é como chamamos a comida nas roças de santo.

${ }^{8}$ Chifres de boi.
} 
DOI: $10.12957 /$ e-mosaicos.2018.33325

No universo brasileiro negro da diáspora, a festa está até na hora da morte, nos rituais de axexê do candomblé e no popular gurufim ${ }^{9}$ dos sambistas. Porque está nos corpos, nas lutas, na rua, nas disputas, nas reinvenções, como me escreveu minha orientadora do Doutorado Stela Caputo, depois de ler um artigo meu. Já percebendo que a pesquisa se estava encaminhando para além do pensado, novamente transbordando, Stela funcionou determinantemente como aquele excedente de visão de que nos fala Bakhtin $(1997,2008)$, Enxergando o que está à nossa volta, por trás, o que ainda estava por perceber. Resolvi apontar o ofá de Logum Edé10 ${ }^{10}$ Orixá do orientando e da orientadora, para abrir as possibilidades de um caminho, confiando na pontaria do menino, e seguir pelos transbordamentos da festa, certo de que serão prósperos.

\section{MAS QUE FESTA É ESSA?}

$\mathrm{Na}$ disciplina do mestrado Redes educativas e culturais, cotidianos e currículos, ministrada pelo professor Paulo Sgarbi, li em um texto de Henri Lefebvre algo como a festa ser desmerecida pelas elites, desvalorizada, como se fosse esvaziada de potência, de valores. Para além da tentativa de invisibilidade, de serem produzidas como inexistência, conforme nos apontou Boaventura dos Santos (2008, 2010) sobre a Ciência em relação a alguns saberes, penso que há outro ponto importante nesse jogo de negligências; cientes de todo o poder de transformação e congregação de pessoas, as forças dominantes tentam minar as festas para que não consigam concentrar, reunir as pessoas.

Procurando por esse texto de Lefebvre, deparei-me com A Festa e a Cidade, de Marcos Felipe Sudré Souza. Baseado na obra de Lefebvre, Souza busca, entre outras reflexões, "discutir a Festa como forma de experimentação da cidade, do espaço urbano vivo, tão necessário para o homem". (SOUZA, 2010, p. 9). Segundo o autor, essa experimentação se dá de várias formas e revela a importância das experiências corporais nos processos, revelando a dimensão cultural da cidade.

Mas que festa será essa? O que será preciso para que a festa seja considerada festa? Quem são os agentes da festa? Será que as festas no Rio de Janeiro de prefeitura evangélica fundamentalista são capazes de disputar a cidade, ocupando praças, parques e ruas? Os sujeitos, quando pensam e fazem festa estão objetivando essa disputa, conscientes de todas as potencialidades de valorização e recriação de identidades ou visam apenas ao entretenimento? Essas são algumas questões que me aparecem e me motivam a pesquisar.

\footnotetext{
${ }^{9}$ Sobre o tema, há o artigo "Festa e morte: um olhar sobre redes educativas e rituais fúnebres afrodescendentes", (MARCELINA e SANFILIPPO, 2017) apresentado comunicação oral no Seminário Redes 2017 e disponível para leitura em https://www.academia.edu/33679415/Festa e morte um olhar sobre redes educativas e rituais $\mathrm{f}$ $\%$ C3\%BAnebres afrodescendentes.

${ }^{10}$ Logum Edé - Orixá menino, tido como filho de Oxóssi, o Caçador, e de Oxum, a dona das águas doces, é também um Odé, um caçador.
} 
DOI: $10.12957 /$ e-mosaicos.2018.33325

O que podemos aprender com as festas dos candomblés sobre a história dos negros, sobre as negociações e as lutas, sobre os afetos e desafetos, sobre as redes educativas que se tecem nos terreiros? E as festas nas ruas e praças? Serão elas transbordamentos de memórias corporais festivas ancestrais, como as festas de candomblé? Que redes educativas tecem? Na escola, como a festa resiste e reexiste? As rodas do Tambor de Cumba, os ensaios do Tambores de Olokun, as rodas do Afrolaje podem ser consideradas festas? O que pensa a Companhia de Aruanda quando ocupa do espaço sob o viaduto Negrão de Lima com seu Fuzuê? Como surgiu o Fuzuezinho, o Fuzuê para crianças? E a Quitanda de Vungi no candomblé Congo-Angola de Mam'etu Mabeji no Kupapa Unsaba? O que nos tem a dizer o professor Carlos Alarcão, iniciado em candomblé dessa raiz, a respeito das possibilidades de sua Quitanda da Leitura ${ }^{11}$ ? Quais as dificuldades de se ocupar os espaços no Rio de Janeiro, como a Pedra do Sal, a Praça Tiradentes, a Praça da Harmonia, o Largo das Neves, a Praça Paulo da Portela, o Largo de São Francisco da Prainha, desde sempre, mas, principalmente, nesses tempos de prefeitura evangélica neopentecostal? Como é fazer festa para Raphael Vidal, idealizador de Festejos Cariocas, Populário, FIM $^{12}$ e tantas outras formas de ocupação do espaço da cidade do Rio de Janeiro? Essas são também perguntas que impulsionam minha pesquisa.

\section{Cotidianos}

A linha de pesquisa de Mestrado, bem como a de Doutorado em andamento, é Cotidianos, Redes Educativas e Processos Culturais, no PropEd/UERJ. Consideramos que pesquisar com os cotidianos exija uma sensibilidade para que possamos dar conta da dinamicidade que as vidas dos sujeitos da pesquisa, atentos às riquezas e belezas que se nos apresentem. Assim, as metodologias não devem aprisionar a pesquisa e, sim, se colocarem a serviço dela. Ferraço (2007) nos ajuda a pensar no cuidado a respeito das pesquisas com os cotidianos:

Está aí nosso maior desafio: Qual a legitimidade no uso de estruturas para falar de algo que é efêmero, incontrolável, caótico e imprescindível? Qual o sentido em extrair conceitos, atribuir classificações, estabelecer relações hierárquicas, propor estruturas conceituais ao permanente devir cotidiano? (FERRAÇO, 2007, p.77).

\footnotetext{
${ }^{11}$ Quitanda da Leitura é a festa de contação de histórias concebida pelo professor Carlos Alarcão, baseada na Quitanda do Erê, festa do Candomblé de raiz Congo/Angola.

${ }^{12}$ Fim de Semana do Livro no Porto. Disponível em: https://projetocolabora.com.br/cultura/ao-invesde-manifestacao-faco-festa
} 
DOI: $10.12957 /$ e-mosaicos.2018.33325

Pensamos que a metodologia do encontro (PASSOS, 2013) nos ajude nessa caminhada. Segundo ela, desses momentos laços e alianças são estabelecidas, e emergem saberes e sujeitos muitas vezes invisibilizados. A Observação Participante, bem como entrevistas, são passos e ferramentas importantes da pesquisa. Sobre isso, Neto e Amaral (2011, p.502), nos alertam: "Claro que uma entrevista etnográfica requer muito mais que uma simples conversa. Ela é de fato interativa, mas precisa um esforço do entrevistador para não induzir a resposta do informante.".

O autor e a autora, em seu texto que trata de Etnografia Religiosa, enfatizam, também, a importância e a dificuldade de estar envolvido, inserido e, ao mesmo tempo, distanciado do universo pesquisado.

A perspectiva da análise que passa a enfatizar os micros processos do cotidiano faz com que se adote uma concepção de desconstrutor do construído e posteriormente fazer sua reconstrução. Como tal, o problema de desconstruir as ações dos diferentes atores sociais é o mais difícil de desvencilhar.

É com esse caráter de desbravador e construtor que devemos praticar no campo religioso, principalmente no Brasil, a famosa expressão "sempre estar com um pé fora e um pé dentro do campo (NETO; AMARAL, 2011, p. 503-504).

Na pesquisa com as festas, os universos ditos religiosos e profanos são quase inseparáveis. Como considero as manifestações da afrodiaspóricas ricos e belos transbordamentos de memórias corporais ancestrais dos terreiros religiosos, não enxergo esses universos separadamente. Ainda que considerasse a separação, sendo Religioso e brincante das festas das ruas, largos e praças, preciso estar atento ao desafio de desbravar e construir de dentro e de fora, com os sujeitos da pesquisa e suas mais variadas e ricas belezas.

Fuzuê, Kizomba, Xirê são exemplos de nomes africanos para festa, confraternização, brincadeira. Todas essas experiências corporais festivas nos contam sobre a cidade que somos nós. Em seu O Terreiro e a Cidade, Sodré (1988), refletindo sobre 0 axé - a força para os nagôs -, as relações ritualísticas coletivas e 0 potencial da festa, apresenta o conceito de corpo-território:

todo indivíduo percebe o mundo e suas coisas a partir de si mesmo, de um campo que lhe é próprio e que se resume, em última instância, a seu corpo. O corpo é o lugar-zero do campo perceptivo, é um limite a partir do qual se define um outro, seja coisa ou pessoa. 0 corpo serve-nos de bússola, meio de orientação com referência aos outros. Quanto mais livre sente-se um corpo, maior o alcance desse poder de orientar-se por si mesmo, por seus próprios padrões (SODRÉ, 1988, p. 123). 
Figura 4: Fuzuezinho

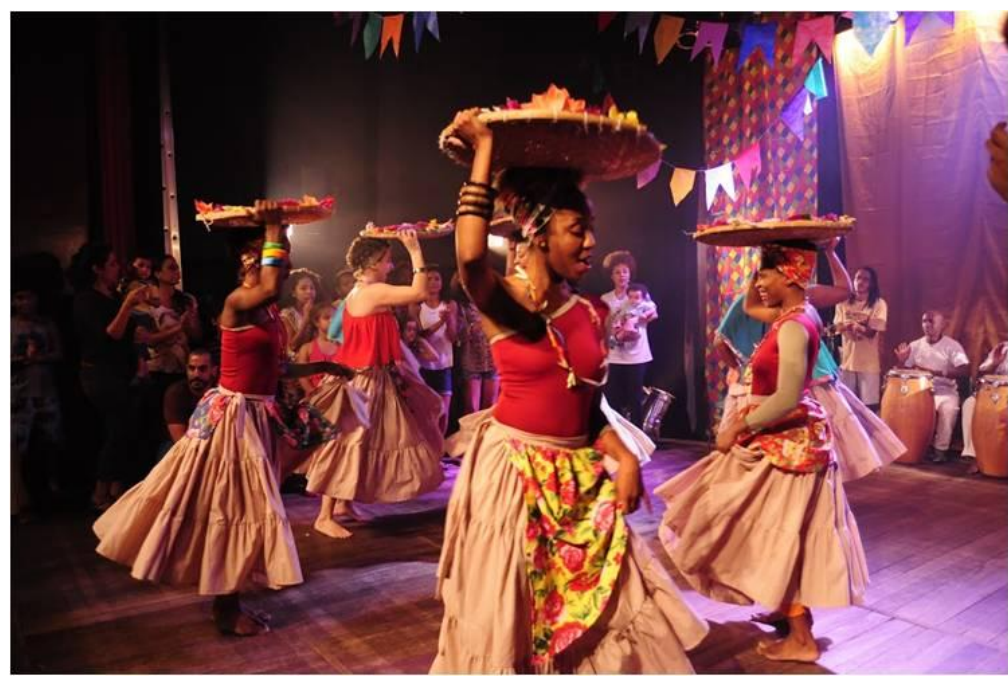

Fonte: Foto Paula Eliane, cedida ao Autor.

Sodré chama atenção para a liberdade e a força coletiva, ritual, desses $\operatorname{corpos}^{13}$, de que falei anteriormente, e que percebo fortemente nas culturas populares transbordadas dos terreiros religiosos:

O ser ritualístico implica o indivíduo constituído como elo numa cadeia de forças que envolve deuses, ancestrais e descendentes (...). O procedimento ritualístico é tanto uma reiteração quanto uma atualização da Origem, porque através dele a tradição confronta, no aqui e agora, na singularidade das vivências, a mobilidade histórica (SODRÉ, 1988, p. 106).

Nas festas de candomblé, nas danças litúrgicas, por exemplo, passagens míticas ancestrais são rememoradas, re-vivenciadas, recriadas. Com as culturas populares como capoeira, jongo, maracatu, coco, congado, samba, essas memórias ancestrais são igualmente celebradas e negociadas com as condições dos tempos e espaços em que se dão. E resistem. E reexistem. Talvez por isso, por notarem as forças mobilizadas nos rituais litúrgicos ou nas confraternizações populares ditas profanas, os poderes hegemônicos, desde sempre, têm se preocupado em minar a liberdade dos corpos, domesticando-os, disciplinando-os. Agindo nas brechas, o povo tem dado seu jeito e festejado. Afinal, como disse Luiz Antonio Simas: "nós somos herdeiros dos homens que bateram tambor na fresta e criaram a subversão pela festa" (SIMAS, 2014, p. 37).

\footnotetext{
${ }^{13}$ Sabino e Lody já haviam apresentado o conceito de corpo cultural, que usei no Mestrado e que "retrata um lugar, um tempo histórico, atividades, profissões, religiosidade, ludismo, rituais de sociabilidade e formas de comunicação" (SABINO, LODY, 2011, p. 15).
} 


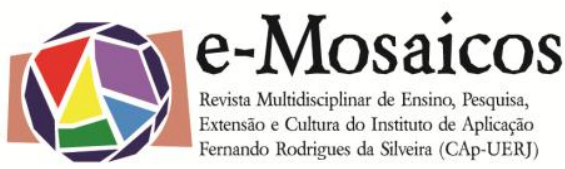

DOI: $10.12957 /$ e-mosaicos.2018.33325

Também de Simas, em parceria com Rufino, é o texto Cidade é Terreiro. Nele, os autores reivindicam epistemologias das macumbas e denunciam:

A gerência de uma cidade praticada pluralmente por uma perspectiva contrária a diversidade produz um efeito de desencante, perda de potência vital, que reifica as raízes mais profundas do colonialismo. A grande peleja que se trava nesse momento veste o véu das purezas dos "homens de bem" para descredibilizar o nosso pluralismo e nossas sabedorias táticas operadas nas frestas (SIMAS; RUFINO, 2017). ${ }^{14}$

E continuam:

Lembremos que os terreiros são as saídas inventivas, a partir da prática do tempo/espaço por aqueles que rasuram as lógicas da desterritorialização. Dessa forma, a experiência do desterro se dá via retirada compulsória e também pelas vias da descredibilização do ser e de seus saberes enquanto possibilidades (SIMAS; RUFINO, 2017). ${ }^{15}$

\section{Considerações Finais}

Cidade é Terreiro. Terreiro é cidade. Corpo é território. O corpo tem se reinventado pela festa, seja nos terreiros, nas ruas, praças, largos e parques. 0 corpo, que dança, canta, toca, sente cheiros e texturas, vibra, amarra laços, pinta, colore, cozinha, come, também experimenta.

Esse corpo, pensando em Rio de Janeiro, predominantemente negro, descendente de africanos de diversas nações, têm, em sua resistência, reencantado o dia a dia. É ele que, nas frestas, criou a umbanda e o candomblé, e ginga nas capoeiras. É ele que samba, jonga, dança coco e maracatu. Esse corpo que dribla é que tem sofrido inúmeras tentativas de domesticação, nas escolas, nas ruas e tem, ainda hoje, sua festa criminalizada.

Se não é pela força da Lei ${ }^{16}$ que permitia a invasão de terreiros e apreensão de símbolos sagrados pela polícia, é pela omissão das autoridades - algumas evangélicas fundamentalistas - quando invadidos, quebrados e incendiados por neopentecostais desviados dos ensinamentos de suas divindades. Se não é pela criminalização da capoeira, do samba e da vadiagem, é por decretos, como o 43.219, do prefeito Marcelo Crivella, intitulado RIAMFE - Rio Ainda Mais Fácil, que pretendia "facilitar" a realização de eventos pela cidade, centralizando as autorizações no

${ }^{14}$ Disponível em http://hisbrasileiras.blogspot.com.br/2016/10/a-cidade-e-terreiro.html. Acesso em 4/10/2017.

${ }^{15}$ Disponível em http://hisbrasileiras.blogspot.com.br/2016/10/a-cidade-e-terreiro.html. Acesso em 4/10/2017.

${ }^{16}$ Por exemplo, o código penal de 1890, que criminalizava a capoieira e a vadiagem e a Delegacia de Costumes, Tóxicos e Mistificações, criada em 1934. 
DOI: $10.12957 /$ e-mosaicos.2018.33325

gabinete do prefeito, mas que, na prática, atrapalham ainda mais a ocupação das ruas com a festa; é pela tentativa de invisibilização de suas redes educativas, da dificultação da implementação das Leis 10639 e 11645.

Sobre o cumprimento das referidas Leis, entendo a festa, como a junina, plena de potência na tessitura de redes afetivas e pedagógicas também na escola. Na dissertação de Mestrado, trouxe a falta apontada por meu filho, quando sentia falta da dança no colégio. A festa estava sendo, aos poucos, retirada do cotidiano escolar e, com ela, todas as suas possibilidades.

A pesquisa, como dito, tem o Ofá apontado para a festa e suas potencialidades, inclusive a de disputar a cidade com essa aura retrógrada, conservadora. Para a festa que liberta, celebra ancestralidades, negocia com as possibilidades, cria e recria identidades, valorizando lutas e encantando a vida. Para a festa que pode disputar a escola, reencantando as redes educativas e fazendo conversarem os tantos saberes de dentro e de fora de seus muros. Aponta, enfim, para a cidade-terreiro que luta e assume o corpo como templo, território de produção de conhecimentos e tessitura de afetos.

\section{REFERÊNCIAS}

BAKHTIN, Mikhail. Estética da criação verbal. 2. ed. São Paulo: Martins Fontes, 1997. . Problemas da poética de Dostoiévski. 5.ed. Rio Janeiro: Forense Universitária, 2008.

CAPUTO, Stela Guedes. Educação nos Terreiros: e como a escola se relaciona com crianças de candomblé. Rio de Janeiro: Pallas, 2012.

FERRAÇO, Carlos Eduardo. Pesquisa com o cotidiano. In: Educação \& Sociedade, Campinas. Vol 28, n. 98, p. 73-95, jan/abr. 2007. Disponível em www.cedes.unicamp.br.

MARCELINA, Elaine; SANFILIPPO, Lucio Bernard. Festa e morte: um olhar sobre redes educativas e rituais fúnebres afrodescendentes. In: Anais do IX Seminário Internacional As Redes Educativas e as Teconologias. Proped/UERJ, 2017.

NETO, Arlindo de Souza; AMARAL, Polyanny Lílian. Os Imponderáveis da Etnografia Religiosa: uma Análise Sobre o Trabalho Etnográfico no Campo da Religião. Mneme - Revista de Humanidades, 11 (29), 2011 - Jan/ Julho. Disponível em www.periódicos.ufrn.br/ojs/index.php/mneme. 
DOI: $10.12957 /$ e-mosaicos.2018.33325

PASSOS, Mailsa Carla Pinto. Encontros cotidianos e a pesquisa em Educação: relações raciais, experiência dialógica e processos de identificação. In: Educar em Revista, Curitiba, n. 51, p. 227-242, jan./mar. 2014.

SABINO, Jorge; LODY, Raul. Danças de matriz africana: antropologia do movimento. Rio de Janeiro: Pallas, 2011.

SANFILIPPO, Lucio Bernard. Agueré: caminhos de transbordamento na afrodiáspora. Mestrado em Educação (Dissertação). Rio de Janeiro: Proped/UERJ, 2016.

SANTOS, Boaventura de Sousa. Um discurso sobre as ciências. São Paulo: Cortez, 2010.

2008.

A gramática do tempo: para uma nova cultura política. São Paulo: Cortez,

SIMAS, Luiz Antonio. Pedrinhas miudinhas. ensaios sobre ruas, aldeias e terreiros.

Rio de Janeiro: Mórula Editorial, 2013.

SIMAS, Luiz Antonio; RUFINO, Luiz. A Cidade é Terreiro. Disponível em

http://hisbrasileiras.blogspot.com.br/2016/10/a-cidade-e-terreiro.html. Acesso em 4/10/2017.

SODRÉ, Muniz. O Terreiro e a Cidade. Petrópolis: Vozes, 1988.

SOUZA, Marcos Felipe Sudré. A Festa e a Cidade. Belo Horizonte: Escola de Arquitetura da UFGM, 2010.

Recebido em 22 de março de 2018

Aceito em 27 de março de 2018 